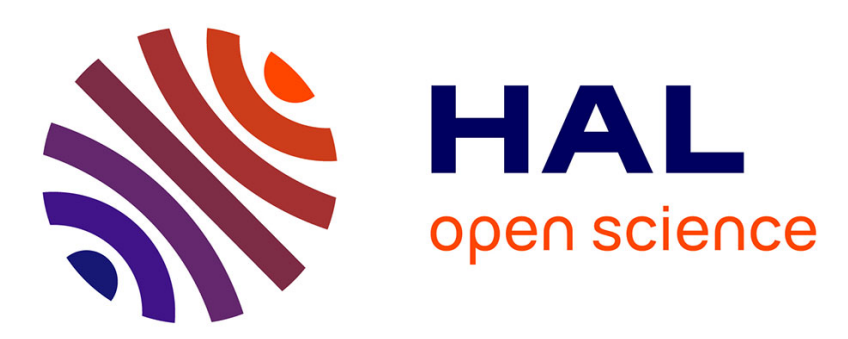

\title{
Uncertainty Analysis for Target SIL Determination in the Offshore Industry
}

Kwangpil Chang, Sungteak Kim, Daejun Chang, Junkeon Ahn, Enrico Zio

\section{To cite this version:}

Kwangpil Chang, Sungteak Kim, Daejun Chang, Junkeon Ahn, Enrico Zio. Uncertainty Analysis for Target SIL Determination in the Offshore Industry. Journal of Loss Prevention in the Process Industries, 2015, 34, pp.151-162. 10.1016/j.jlp.2015.01.030 . hal-01259668

\section{HAL Id: hal-01259668 https://hal.inria.fr/hal-01259668}

Submitted on 20 Jan 2016

HAL is a multi-disciplinary open access archive for the deposit and dissemination of scientific research documents, whether they are published or not. The documents may come from teaching and research institutions in France or abroad, or from public or private research centers.
L'archive ouverte pluridisciplinaire HAL, est destinée au dépôt et à la diffusion de documents scientifiques de niveau recherche, publiés ou non, émanant des établissements d'enseignement et de recherche français ou étrangers, des laboratoires publics ou privés. 


\title{
Uncertainty Analysis for Target SIL Determination in the Offshore Industry
}

\author{
KwangpilChang ${ }^{a}$, Sungteak Kim ${ }^{a}$, Daejun Chang ${ }^{b^{*}}$, Junkeon Ahn' ${ }^{b}$, Enrico Zio \\ ${ }^{a}$ Hyundai Heavy Industries, Yongin, Korea \\ ${ }^{\mathrm{b}}$ Korea Advanced Institute of Science and Technology, Daejeon, Korea \\ ${ }^{\mathrm{C}}$ Chair on Systems Science and the Energy challenge, European Foundation for New Energy- \\ Electricité de France, EcoleCentrale Paris and Supelec / Laboratory of Industrial Engineering, \\ EcoleCentrale Paris, Grande Voie des Vignes, F92-295, ChatenayMalabryCedex / Politecnico di \\ Milano, Energy Department, Nuclear Section, c/o Cesnef, via Ponzio 33/A, 20133, Milan, Italy
}

\begin{abstract}
The requirements on thedesign of SISs(Safety Instrumented Systems) based on SIL(Safety Integrity Level) have been developed continuously in the offshore industry. IEC 61508 and IEC 61511 illustrate various methodologies to determine the target SIL for specified safety functions, such as risk graph,layer of protection analysis, etc. These methods could arrive at different target SILs for the same safety function, mainly due to uncertainty in the models. In addition, uncertainties in the input parameters contribute to uncertainty in the target SIL. In the offshore industry, engineers usually utilize two or more methods to assess target SILs for the same function and take the most conservative value as the target SIL. In this paper, we investigate on the uncertainty in determining target SILs evaluatedby the risk graph method, Minimum SIL Table from OLF 070 and LOPA. A procedure of SIL determination accounting for uncertaintiesis proposed for the risk graph method, Minimum SIL Table from OLF 070 and LOPA by using a Fuzzy Set approach only and the combination of Monte Carlo simulation and Fuzzy Set approach.
\end{abstract}

Keywords: SIL Determination, Uncertainty Analysis, Offshore Industry, Risk Graph Method, Minimum SIL Table from OLF70, LOPA, Fuzzy Set, Monte Carlo Simulation.

\section{INTRODUCTION}

The importance of safety systems has been increasing in the oil and gas industry [1]. In general, safety systems, different and independent from each other, are considered for providing multiple protection layers. The typical multiple protection layers installed in oil and gas facilities are:

- BPCS (Basic Process Control System)

- SIS (Safety Instrumented System)

- Physical Mitigation System

BPCS is a system which handles process control and monitoring for oil and gas facilities. Among the various multiple protection layers, SIS is the most important and critical protection layer to prevent or reduce the risk of abnormal process conditions, which may be hazardous. SIS isinstalledfor reducing risks to allowable levels by detecting hazardous events and taking actions to prevent them from developing into further accidents. SIS is a safety system that includes an electrical, electronic or programmable electronic component to keep "people", "environment", "assets" in safe conditions during oil and gas facility operation periods. Elements of SIS consist of initiators, a logic solver, and final elements, as illustrated in Figure 1.A variety of SISs are installed in the oil and gas plants, for example, fire \& gas systems, emergency shutdown systems and process shutdown systems. SIS is the next layer of protection following BPCS and alarm / operator intervention. 


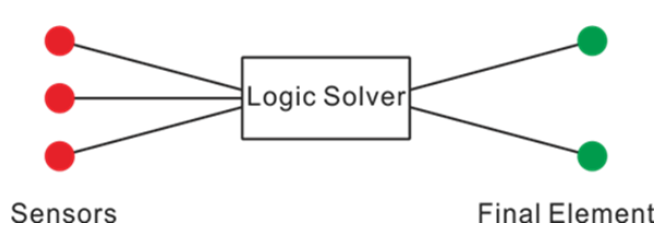

Figure 1. Safety Instrumented System

According to IEC 61508/61511[2, 3], the overall required safety management and technical activities are related to the safety life cycle. The safety life cycle consists of a number of steps which can be grouped into three phases, "analysis", "realization" and "operation" in Figure 2. The purpose of the analysis phase is to identify hazards and specify safety requirements of SIS. Safety requirements specification (SRS) of SIS should contain critical information, which include functional description of each Safety Instrumented Function (SIF), target SIL, mitigated hazards, process parameters, maintenance requirements, response time, etc.The next phase of the safety life cycle is the realization of SIS based on SRS results. All performance targets and functional requirements defined in the SRS are key information for the design, installation and operation of SIS.The defined target SIL would affect the whole SIS lifecycles, including design and operation, since these target values draw the upper limit of the reliability performance. From this point of view, target SIL should be derived carefully in order to not only satisfy the required risk reduction but also to get rid of unnecessary additional SISs upon existing safety systems, which are already in place.

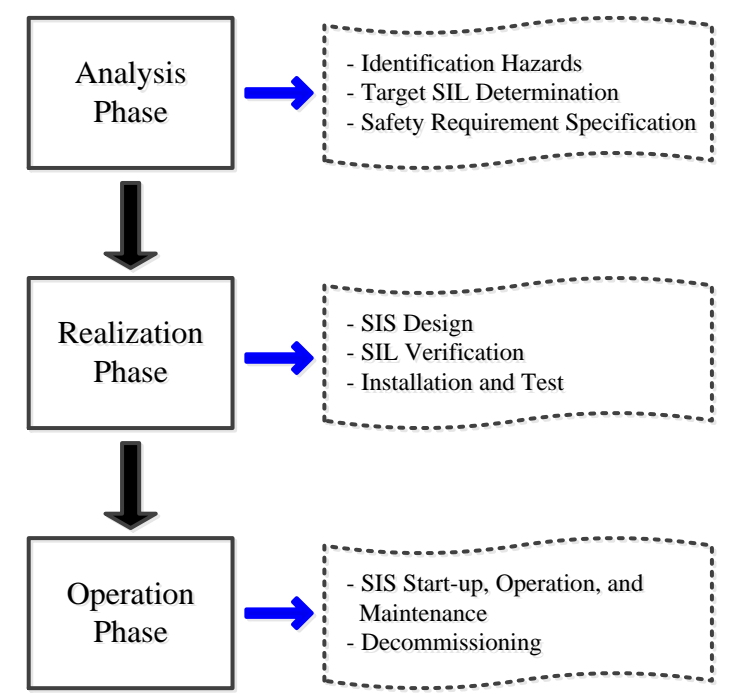

Figure 2.Safety Lifecycle Approach regarding SIL

As shown in Figure 3, the determination of the target SIL is an important task of the analysis phase of the safety lifecycle. According to IEC 61511, when determining SIL requirement for each identified SIF, one of thefollowing methods can be used $[2,3]$ :

- Risk Graph

- LOPA (Layer of Protection Analysis)

- Risk Matrix

The criteria for selecting the method is as follows: complexity of the application, guideline of regulatory authorities,nature of the risk and required risk reduction,expertise and experience of the personnel,availability of information on the risk-related parameters and whether the required risk reduction is given explicitly in a numerical form or in a qualitative form. OLF 70 provides"Minimum SIL requirements" based on the existing performance level [4]. OLF 70 hastheadvantage to give 
standardization for the determination of the SIL of a safety function compared with methods suggested in IEC 61511.

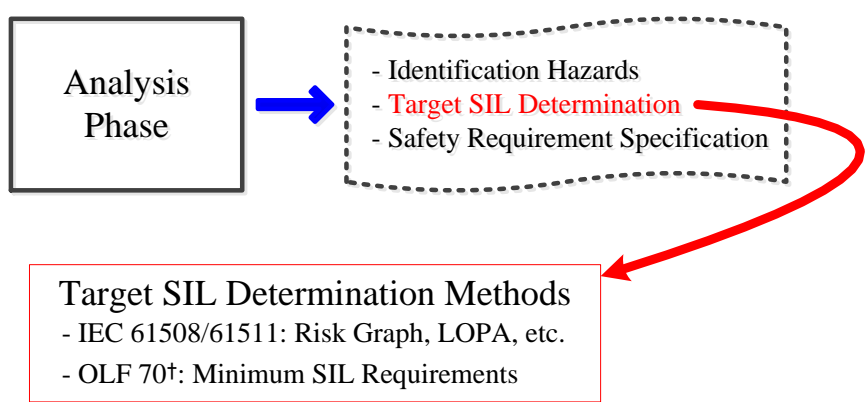
Figure 3. SIL Determination Methods ( $\dagger:$ Application of IEC61508/61511 in the Norwegian Petroleum
Industry)

The above mentioned methods have both advantages and disadvantages with respect to rigor and effort, fit with SIL lifecycle, inputs required, etc. Basically, the above methods are required to show consistency in target SIL determination.For example, if a SIF is identified from a SIL determination workshop, the target SIL for this SIF should be the same regardless of the persons who perform the SIL determination and the used methods. As mentioned before, in practice, the more conservative SIL is often assigned as target SIL to resolve the problem of inconsistency in the results of the analysis by offered methods. This approach of conservatism would help a system have sufficient safeguards and keep it safe. However, excessive conservative safety system design may result in increasing cost in terms of CAPEX as well as OPEX, e.g. due to more frequent maintenance.

Assessment of target SIL always involves uncertainties due to the nature of the analysis process: qualitative decision-making based on some statistical data and expert opinion. Assessing and managing these uncertainties should be done carefully to lead the system to be optimized in the sense of setting the appropriate level of system reliability target. Uncertainty analysis for target SIL determination would be the starting point of effective SIL lifecycle management, by checking the uncertainty level in the target SIL and identifying dominant factors which contribute to output uncertainties.

For FPSOs (Floating Production Storage Offloading) which is typical offshore facilities, more than $300 \sim 400$ SIFs (Safety Instrumented Function) which are operated by SISs are usually identified during the early design phase. It is mandatory that a SIL sufficientto ensure safety against unwanted accident events be assigned for all identified SIFs by SIL determination methods. The SIL assignment for all identified SIFs of a FPSO demands long times(on average, it takes one or two weeks to full SIL determination for a FPSO) and significant efforts.

It is important to improve theconfidence level of SIL determination by minimizing uncertainties. In this research, the main motivation of the paper is to propose consistent and traceable SIL determination procedures which can prevent unreasonable trade-offs between safety of facilities and costs due to overestimation or underestimation of the required SISs' performances.

The risk graph is most frequently used for SIL determination in the offshore industry, because it is of easy implementation. The risk graph useslinguistic terms such as 'minor or critical', 'rare or frequent' and 'possible or not likely' for each input parameter's relative importance determination. The use of linguisticterms can help understanding the determination procedures. However, the understanding of linguistic terms for each input parameter can differ among participants to the SIL determination activities, which can lead to subjective results. 
There have been many efforts to enhance the shortcomings of the risk graph method. The Fuzzy Set approach, which is a non-probabilistic method,isconsidered to bean appropriate approach to represent,quantify and analyze the uncertainties of SIL determination [5, 6, 7].

Monte Carlo simulation is most commonly used for probabilistic uncertainty analysis inreliability and risk assessments. However, its application is still limitedin SIL determination and uncertainty analysis, because of lack of sufficient information available for specific probability distribution assignments.

Thehybrid method, a combination of Monte Carlo simulation and fuzzy set approach,has beenconsideredan effective approach for risk assessments and estimation of SIS performance $[8,9]$.

In addition to the risk graph method, minimum SIL Table from OLF 070 and LOPA are used to determine SIL in offshore facilities, although their applications are relatively few compared with the risk graph method. EspeciallyLOPA is a powerful tool to asses SIL of SIFs when it is difficult to get an agreement between participants to the SIL determination studies.

The objectives of this paper are to ( $i$ )identify uncertainty sourcesinSIL determination methods, specifically risk graph method, minimum SIL Table from OLF 070and LOPA, (ii) propose proceduresfor the uncertainty analysis inSIL determination by risk graph method, minimum SIL Table from OLF 070and LOPA, using a Fuzzy Set approach (non-probabilistic method), Monte Carlo simulation (probabilistic method) and a combination of Monte Carlo simulationand the Fuzzy Set approach.

The paper is organized as follows: an introduction to the methods for target SIL determination, which are popular in the offshore industry is given in Section 2,identification of uncertainty factorsand proposed procedures for uncertainty analysis in SIL determination phase are illustrated in Section 3, case studies performed to show the effects of uncertainty are presentedin Section 4, and conclusions with suggestions for future works are offered in Section 5.

\section{TARGET SIL DETERMINATIONBY USING CONVENTIONAL METHODS}

In this section, a short description of some of the most common (conventional) methods used for target SIL determination is given.

\subsection{Risk Graph}

Risk graph isone of the frequently-used methods whendetermining target SIL [10]. The risk graph considers likelihood, consequence, occupancy and probability of personnel avoiding hazardswhile hazard matrices consider only likelihood and consequence of an event. These four parameters used in risk graph are combined to indicate the level of unmitigated risks.

Risk graph is suitable for SIS with defined equipment under control (EUC), which is classified as local safety function. On the other hand, global safety functions cannot be easily estimated through the risk graph whena whole platform is the equipment under control (EUC), e.g. Emergency Shut-down (ESD) and Fire and $\mathrm{Gas}(\mathrm{F} \& \mathrm{G})$ safety functions.

\subsection{LOPA}

LOPA(Layer of protection analysis) is a simplified risk assessment to determine if there are sufficient independent protection layers (IPLs) against anaccident scenario [11]. Many types of protection layers can beconsidered against an unwanted accident.The thickness of the arrows represented in Figure 4 indicates the frequency of thespecified consequence for the initiating event. The results of LOPA can be used for thedecision-making. 


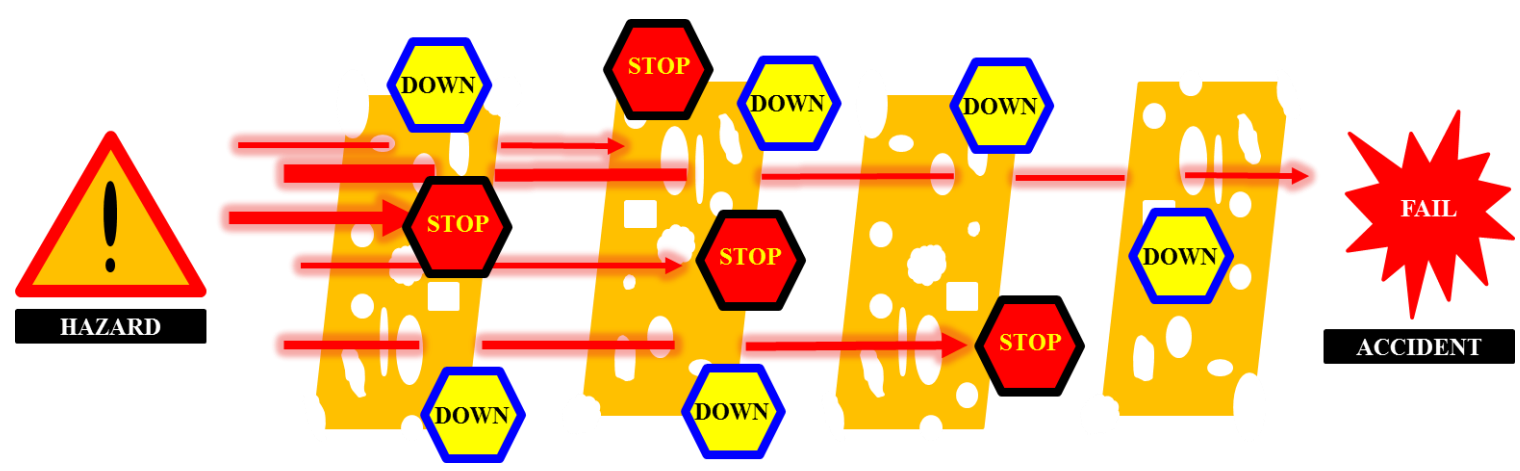

Figure 4. Independent Protection Layers against Accident

The first step of LOPA is to screen and identify the accident scenarios, based on theconsequence analysis. The consequence is typically identified by a qualitative riskassessment such as a HAZOP study.LOPA is applied to one scenario at a time. A scenario starts from an unwanted and unplanned eventresulting in an undesirable consequence. Each scenario has at least two elements: 'aninitiating event' and 'a consequence'. The initiating event must lead to the consequence.

The next step is to identify the initiating event and determine the frequency ofthe event. Initiating events are classified into three types: 'external events', 'equipmentfailures', and 'human failures'. All possible causes from the accident scenario should bereviewed and verified as valid initiating events for the consequence. Examples ofinappropriate initiating events are inadequate operator training/certification, inadequate test and inspection, or unavailability of protection devices.

The enabling events or conditions should be differentiated from the initiating event duringthis step. These consist of operations or conditions that do not directly cause scenarios, butwhich must be present or active in order for the scenarios to proceed.

An IPL is a device, system or action that is capable of preventing a scenario fromproceeding to its undesired consequence. The effectiveness of an IPL is quantified in terms ofits probability of failure on demand. The typical IPLs considered in the process design phase are basic process control systems (BPCSs), critical alarms and human intervention, SIFs, physical protection, and emergency response systems.

Risk is estimated on the basis of the initiating event frequency, probability of failure on demand (PFD) value ofIPL and the consequence value. The frequency for the risk estimation is calculated as follow:

$$
\begin{aligned}
& f_{i}^{C}=f_{i}^{I} \times \prod_{j=1}^{J} P F D_{i j}=f_{i}^{I} \times P F D_{i 1} \times P F D_{i 2} \times \cdots \times P F D_{i j} \\
& f_{i}^{C}: \text { Frequency for consequence } \mathrm{C} \text { for initiating event } i \\
& f_{i}^{I}: \text { Initiating event frequency for initiating event } i \\
& P F D_{i j} \text { : Probability of failure on demand on the } j \text { th IPL }
\end{aligned}
$$

The final step of LOPA is to compare the risk calculated in the previous step to a tolerablerisk criteria or related targets.

\subsection{Minimum SIL Table from OLF 070}

It isdifficult to select the proper methodologywhen applying IEC 61508/61511 standards for determining target SIL. This is due to a variety of methods existing in the standards without detailed 
description or guideline of which method to be used for which case [4]. In addition, experience has shown that the risk-based approach such asrisk graph and/or hazard matrix cannot result in consistent target SIL.

In this point of view, OLF 070 [4]provides minimum SIL tables for target SIL determination. Minimum SIL tablesdeal with the most frequently used safety functions in the oil and gas production plants for both onshore and offshore. The tables illustrate safety function descriptions, functional boundaries and minimum requirements of target SIL. The purpose of minimum SIL requirements is tocheck the minimum safety level of frequently used safety functions,encourage the standardization among the industries, and simplify calculation and documentation.

Minimum SIL requirements are derived based on the typical loop assumption, which only include main items of SIS - sensors, logic solvers, valves and circuit breakers - for SIL calculation and exclude some details e.g. barriers, relays, cables and signal adapters.The minimum SIL values are estimated by using the industrially verified component reliability data [4]. The minimum SIL values can be used as input data to the QRA (Quantitative Risk Assessment). If the overall risk levels, which come from QRA results, are too high, it is possibleto define more stringent requirements because the minimum SIL values are literally the minimum requirements. Thus, during SIL verification phase, genuinely purchased and installed items should be checked in terms of compliance with target SIL.

However, plant specific conditions and technological improvements cause deviations from the minimum SIL requirements. In this case, IEC 61508/61511 could be a solution in terms of SIL determination methodology and documentation.

\section{UNCERTAINTY ANALYSIS IN DETERMINING TARGET SIL}

Some critical considerations on the representation and description of uncertainties in risk assessments can be found in E. Zio and T. Aven [12, 13, 14]. According to these studies, a number of alternative approaches exist, which are classifiedas 'probabilistic methods' and 'non-probabilistic methods' [12, 13], e.g. probabilistic analysis, probability bound analysis, imprecise probability, random sets and possibility theory.

\subsection{Uncertainty Sources}

Uncertainty analysis is performed toestimate the uncertainty in the output of the analysis of a system. In reality, the system under consideration cannot be easily describedperfectly since knowledge of the underlying phenomena is not complete [15]. This leads to uncertainties in both parameters and models [15].

Uncertainty can beclassifiedinto two different types-randomness due to natural variability of systemand imprecision due to lack of knowledge on the system. The former iscalled as aleatory, whereas the latter iscalled as epistemic, as shown in Figure $5[14,15]$.

The epistemic uncertainty can be reducedif new knowledge is available, whilethe aleatory uncertainty cannot be reduced due to its inherent nature [16]. Several typesof uncertainty, which were classified as aleatory in the past,are now considered as epistemic.This indicatesthat the uncertainty classification could vary when understanding of naturalphenomena increases. In spite of limitations, the classification of uncertainty givesa fundamental concept [17]. 


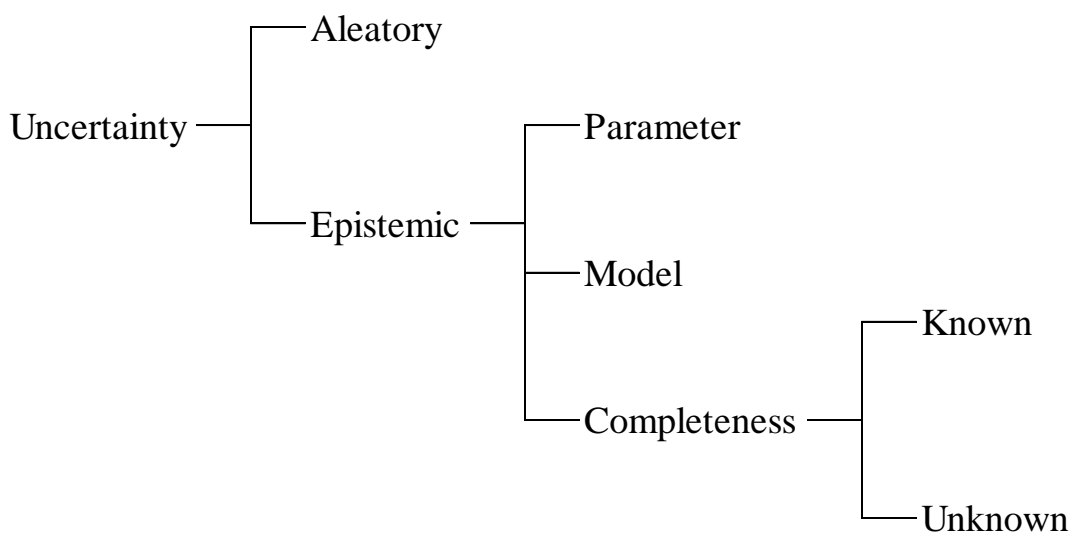

Figure 5.Uncertainty Classification

Parameter uncertainty has been studiedin the literature [1]andis often expressed in terms ofdistributions of the parameter values [17]. The causes of parameteruncertainty can be aleatory and/or epistemic [16]. For aleatory parameter uncertainty, natural variabilityin the values of the parameters can be described byuncertainty distributions, typically probability distributions. For epistemic parameter uncertainty,the analyst's knowledge about the parameters'valuesis described by probabilistic and non-probabilistic distributions[17].

Model uncertainty existssinceamodel is a simplification of the reality based on assumptions [18]. In practice, it becomes also relatedto the fact that several differentmodels may be used to analyze the same system [17].

Completeness uncertainty has the same causes ofmodel uncertainty-assumptions and simplifications [17]. Completeness uncertainty can be distinguished between known and unknown one. The known completeness uncertainty exists due to the factors that are known, but not included for some reasons. The unknown completeness uncertainty, otherwise, exists due to the factors that are not known or not identified as of now. From these concepts, the known completeness uncertainty can be expressed by the impact from the excluded factors. On the other hand, the unknown completeness uncertainty can be measured by the extent of maturity of technology and intelligibility of the environment surrounding the system [17].

\subsection{Uncertainty Classification of SIL Determination Methods}

According to the definitions of uncertainty, various target SIL determination methods can be classified as possibly affected by aleatory/epistemic, parameter/model/known completeness/unknown completeness uncertainty, based on the characteristics of each method. The result of the classification is shown in Table 1 .

The choice of SIL determinationmethods is dependent on the available information, reliability data, required resources, etc. For example, if it is possible to get sufficient information for a reasonable target SIL with full required resources such as time and experiencedexperts, a fully risk-based approach, risk graph,is preferred to other methods.

As described in the previous section, hazard matrixes are most simple models for SIL determination. Risk graphs are an extension of hazardmatrixes. As shown in Figure 6, the concept of SIL determination by using the risk graph method is based on estimation of frequencies of hazardous events, consequences of hazardous events and effectiveness of non-SIS risk mitigation measures. SIL determination by risk graph methods requires consensus on four categorized parameters as follows:

- Consequence risk parameters(C)

- Frequency and risk exposure time parameters(F) 
- Possibility of failing to avoid hazard risk parameters $(\mathrm{P})$

- Possibility of unwanted occurrence parameters(W)

On the other hand, minimum SIL Table or LOPA is a (semi)quantitative method for SIL determination. Minimum SIL Tablesare derived based on the typical loop assumption and are estimated by using the industrially verified component reliability data, including common cause factor, diagnostic coverage and fail-safe design.The PFD calculation model and the required reliability data are contributors to uncertainty for SIL determination by minimum SIL.

Table 1.Uncertainty Sources and their Classification, in SIL Determination Methods

\begin{tabular}{|c|c|c|c|}
\hline Method & Characteristics of Model & Uncertainty Sources & $\begin{array}{l}\text { Completeness } \\
\text { /Randomness }\end{array}$ \\
\hline $\begin{array}{l}\text { Risk } \\
\text { Graph }\end{array}$ & $\begin{array}{l}\text { - } 4 \text { key categorized } \\
\text { parameters combination \& } \\
\text { propagation model based } \\
\text { on consensus } \\
\text { a. Consequence } \\
\text { b. Frequency } \\
\text { c. (or Demand rate) } \\
\text { d. } P_{\text {fail to avoid hazardous }} \\
\text { e. event } \\
\text { f. Occupancy } \\
\text { - Strongly dependent on } \\
\text { analyst' experience and } \\
\text { knowledge }\end{array}$ & $\begin{array}{l}\text { - Categorization of parameters : } \\
\text { linguistic ambiguity } \\
\text { a. Number of categories } \\
\text { b. Ranges of parameter values } \\
\text { for each category } \\
\text { - Inconsistent consensus : } \\
\text { subjectivity } \\
\text { a. Subjectivity: different teams, } \\
\text { different results } \\
\text { b. Competence gap between } \\
\text { teams }\end{array}$ & $\begin{array}{l}\text { - No aleatory } \\
\text { - Epistemic } \\
\text { a. Known/unknown } \\
\text { completeness } \\
\text { b. Model } \\
\text { c. No parameter }\end{array}$ \\
\hline LOPA & $\begin{array}{l}\text { - Assume multiple } \\
\text { independent protection } \\
\text { layer model: Onion model } \\
\text { - Determine enabling events } \\
\text { or conditions from the } \\
\text { initiating event } \\
\text { - Quantify effectiveness of } \\
\text { an independent protection } \\
\text { layer in terms of its PFD }\end{array}$ & $\begin{array}{l}\text { - Independent protection layers } \\
\text { a. Identification of IPLs } \\
\text { b. PFD values for each IPL } \\
\text { - Inconsistent consensus } \\
\text { (for qualitative parameter, C) } \\
\text { a. Subjectivity: different teams, } \\
\text { different results } \\
\text { b. Competence gap }\end{array}$ & $\begin{array}{l}\text { - No aleatory } \\
\text { - Epistemic } \\
\text { a. Known/unknown } \\
\text { completeness } \\
\text { b. Model } \\
\text { c. No parameter }\end{array}$ \\
\hline $\begin{array}{c}\text { Minimum } \\
\text { SIL }\end{array}$ & $\begin{array}{l}\text { - Calculation method: } \\
\text { Reliability block diagram } \\
\text { - Dependent on both SIF } \\
\text { boundary and voting } \\
\text { configurations of each } \\
\text { element }\end{array}$ & $\begin{array}{l}\text { - Parameter values } \\
\text { a. Various reliability database } \\
\text { b. Difference between vendor } \\
\text { data and generic database } \\
\text { - Plant-specific conditions: } \\
\text { Validity of typical SIF }\end{array}$ & $\begin{array}{l}\text { - No aleatory } \\
\text { - Epistemic } \\
\text { a. Known/unknown } \\
\text { completeness } \\
\text { b. Model } \\
\text { c. No parameter }\end{array}$ \\
\hline
\end{tabular}




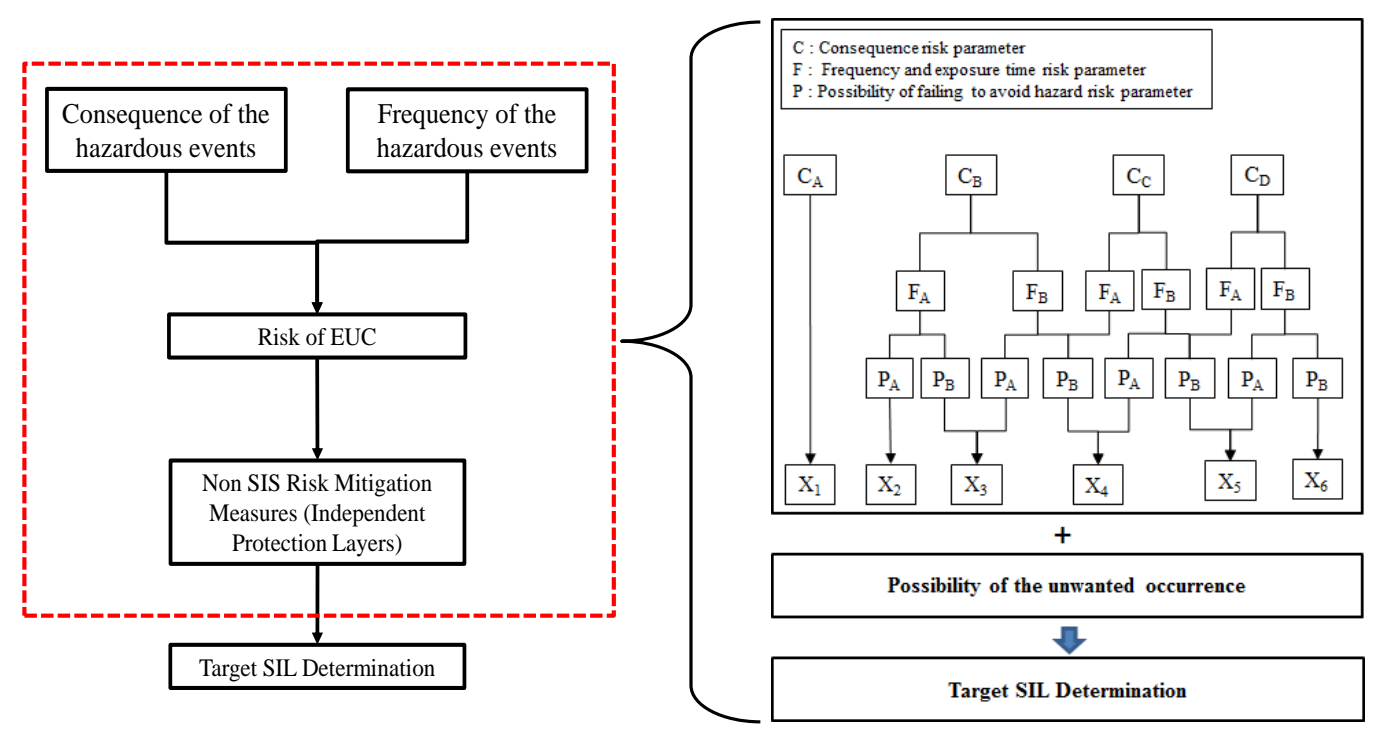

[Risk and safety integrity concept]

[Risk graph method for SIL determination]

Figure 6.SIL Determination Concept by Risk Graph Method

\subsection{Uncertainty Analysis for Target SIL Determination}

Probabilistic methods, non-probabilistic methods and hybrid methods, combination of nonprobabilistic and probabilistic methods are used to perform the uncertainty analysis for target SIL determination in the paper. Specifically, the sampling method, or probabilistic method, is used for OLF 070 due to its quantitative features and the fuzzy set method, or non-probabilistic method, is used for the calibrated risk graph due to its qualitative features. For LOPA, both the sampling method and the fuzzy set method are used and this combined method can be deemed as a hybrid method.

Probabilistic uncertainty analysis can be performed by sampling techniques likeMonte Carlo and Latin Hypercube [18]. Monte Carlo simulation is a method for generating random samples by using a large number of pseudo-random uniform variables from the interval $[0,1]$. Compared to this method, Latin Hypercube sampling is a similar method for random sample generation where an analyst should decide how many sample points to use for a variable by dividing it into some equally probable intervals.

These methods generally involve the generation of randomsamples of input random variables, the deterministic evaluations of the performance function atthese samples, and the post-processing to extract the probabilistic characteristics (e.g., statisticalmoments, reliability, and PDF) of the performance function $[18,20,21]$.

Sampling-based method based on Monte Carlo simulationisapplied to quantitative SIL determination methods of OLF 070 minimum SIL requirement in the paper. Input parameters are modeled as assumed probability distributions and this makes the basis for sampling.

The main steps of SIL determination by using Monte Carlo simulation are [12]:

1) Construct a probability distribution for input parameters (component failure rates, common cause beta-factors, test coverage factors,etc.)

2) Generate sample sets of input parameters by using random numbers

3) Quantify output function of PFD (Probability of Failure on Demand) with the sampled sets

4) Repeat steps 2 to 3 and analysis of relevant statistics: mean, standard deviation, coefficient of variation and $P_{\alpha}(\alpha \%$ percentile $)$ of each output value

The target SIL distribution is assigned with the corresponding PFD values. 
Methods for non-probabilistic uncertainty analysis are based on mathematical principles for knowledge representation reflecting degree of truth and attempt to model the approximate sense of words in the linguistic statements of the analysts [7].The risk graph summarized both in Section 2 and Figure 6 are most frequently used for SIL determination in the offshore industrydue to easy implementation and fast assessments with four input parameters. However, the understanding of linguistic terms for each input parameter can differ between participants during SIL determination activities, which can lead to subjectivity results. The calibrated risk graph is use more quantitative definitions of each input parameter as following Table 2 to supplement the shortcomings of the risk graph method. However, SIL determination results of the calibrated risk graph has dominated by consequence $(\mathrm{C})$ and demand rate $(\mathrm{W})$ parameters, because occupancy $(\mathrm{F})$ and Probability of Avoidance $(\mathrm{P})$ have only two ranges of variability.

Table 2.Definitions of Input Parameters for Calibrated Risk Graph [3]

\begin{tabular}{cl}
\hline Input Parameter & \multicolumn{1}{c}{ Classification } \\
\hline Consequence & $\mathrm{C}_{\mathrm{A}}:<0.01$ \\
\hline & $\mathrm{C}_{\mathrm{B}}: 0.01 \sim 0.1$ \\
& $\mathrm{C}_{\mathrm{C}}: 0.1 \sim 1$ \\
& $-\mathrm{C}_{\mathrm{D}}:>1$
\end{tabular}

The application of fuzzy set has most continuously studied among non-probabilistic methods to improve the shortages of the risk graph method including to the calibrated risk graph methoddue to characteristics to handling the ambiguous or imprecise, and uncertain input parameters $[5,6,7]$.

The overall procedures of fuzzy set approach for SIL assessment used in the paper consist of three sub steps [5].

1) Fuzzification : Generation of membership function for four risk parameters including development of the fuzzy scales

(1) Degree of membership vs. Fatalities per event (Consequence, C)

(2) Degree of membership vs. \% of Exposure (Exposure, F)

(3) Degree of membership vs.Probability of avoidance(Avoidance, P)

(4) Degree of membership vs. Demand rate(Demand rate, W)

5 Degree of membership $v s$. SIL

2) Fuzzy inference : Derivation of the fuzzy rules using 'If-then rule' 
If fuzzy inference is considered based on the combination of fourinput parameters and the risk graph model, total of 52 fuzzy rules are generated as summarized in Table 3. For example, the rule \#13 indicates that if $\mathrm{C}$ is $\mathrm{C}_{\mathrm{B}}$ and $\mathrm{F}$ is $\mathrm{F}_{\mathrm{B}}$ and $\mathrm{P}$ is $\mathrm{P}_{\mathrm{A}}$ and W is $\mathrm{W}_{0}$ then SIL is SIL 2.

3) Defuzzification : Determination of point values and assessment of uncertainty

Table 3.Fuzzy Rule Generation Results based on Calibrated Risk Graph Model

\begin{tabular}{|c|c|c|c|c|c|c|}
\hline \multirow{2}{*}{ Rule } & & \multicolumn{5}{|c|}{ 'If-then' } \\
\hline & & $\mathrm{C}$ & $\mathrm{F}$ & $\mathrm{P}$ & W & SIL \\
\hline \multirow{4}{*}{1 Group } & 1 & \multirow{4}{*}{$\mathrm{C}_{\mathrm{A}}$} & & & $\mathrm{W}_{0}$ & $\mathrm{a}$ \\
\hline & 2 & & & & $\mathrm{~W}_{1}$ & - \\
\hline & 3 & & & & $\mathrm{~W}_{2}$ & - \\
\hline & 4 & & & & $\mathrm{~W}_{3}$ & - \\
\hline \multirow{4}{*}{2 Group } & 5 & \multirow{4}{*}{$\mathrm{C}_{\mathrm{B}}$} & \multirow{4}{*}{$\mathrm{F}_{\mathrm{A}}$} & \multirow{4}{*}{$\mathrm{P}_{\mathrm{A}}$} & $\mathrm{W}_{0}$ & 1 \\
\hline & 6 & & & & $\mathrm{~W}_{1}$ & $\mathrm{a}$ \\
\hline & 7 & & & & $\mathrm{~W}_{2}$ & - \\
\hline & 8 & & & & $\mathrm{~W}_{3}$ & - \\
\hline \multirow{4}{*}{3 Group } & 9 & \multirow{4}{*}{$\mathrm{C}_{\mathrm{B}}$} & \multirow{4}{*}{$\mathrm{F}_{\mathrm{A}}$} & \multirow{4}{*}{$\mathrm{P}_{\mathrm{B}}$} & $\mathrm{W}_{0}$ & 2 \\
\hline & 10 & & & & $\mathrm{~W}_{1}$ & 1 \\
\hline & 11 & & & & $\mathrm{~W}_{2}$ & $\mathrm{a}$ \\
\hline & 12 & & & & $\mathrm{~W}_{3}$ & - \\
\hline \multirow{4}{*}{4 Group } & 13 & \multirow{4}{*}{$\mathrm{C}_{\mathrm{B}}$} & \multirow{4}{*}{$\mathrm{F}_{\mathrm{B}}$} & \multirow{4}{*}{$\mathrm{P}_{\mathrm{A}}$} & $\mathrm{W}_{0}$ & 2 \\
\hline & 14 & & & & $\mathrm{~W}_{1}$ & 1 \\
\hline & 15 & & & & $\mathrm{~W}_{2}$ & $\mathrm{a}$ \\
\hline & 16 & & & & $\mathrm{~W}_{3}$ & - \\
\hline $\begin{array}{c}5 \sim 11 \\
\text { Group }\end{array}$ & $\cdots$ & $\cdots$ & $\cdots$ & $\cdots$ & $\cdots$ & $\cdots$ \\
\hline \multirow{4}{*}{12 Group } & 45 & \multirow{4}{*}{$\mathrm{C}_{\mathrm{D}}$} & \multirow{4}{*}{$\mathrm{F}_{\mathrm{B}}$} & \multirow{4}{*}{$\mathrm{P}_{\mathrm{A}}$} & $\mathrm{W}_{0}$ & $\mathrm{~b}$ \\
\hline & 46 & & & & $\mathrm{~W}_{1}$ & 3 \\
\hline & 47 & & & & $\mathrm{~W}_{2}$ & 2 \\
\hline & 48 & & & & $\mathrm{~W}_{3}$ & 1 \\
\hline \multirow{4}{*}{13 Group } & 49 & \multirow{4}{*}{$\mathrm{C}_{\mathrm{D}}$} & \multirow{4}{*}{$\mathrm{F}_{\mathrm{B}}$} & \multirow{4}{*}{$\mathrm{P}_{\mathrm{B}}$} & $\mathrm{W}_{0}$ & $\mathrm{~b}$ \\
\hline & 50 & & & & $\mathrm{~W}_{1}$ & $\mathrm{~b}$ \\
\hline & 51 & & & & $\mathrm{~W}_{2}$ & 3 \\
\hline & 52 & & & & $\mathrm{~W}_{3}$ & 2 \\
\hline
\end{tabular}

A non-probabilistic method of uncertainty representation should be used with the risk graph method, because experts' opinion is the key factor [24].LOPA is another appropriate method to apply sampling technique due to its quantitative feature. However, LOPA has also qualitative features simultaneously. To reflect this qualitative feature into the uncertainty modeling, fuzzyrepresentation should be utilized in combination with a sampling-based method.

The combination of fuzzy set approach and Monte Carlo simulation has been performed to assess the uncertainty in risk assessment, combining probability density functions of random variables and membership functions of fuzzy variables [9]. The PFD calculation of SIS can be done by combining Monte Carlo and fuzzy set on input parameters like component failure rates, diagnostic coverage, common cause failure factor, mean time to repair a detected failure and proof-test interval. The sample set of each input parameteris generated by Monte Carlo simulation and then, fuzzy arithmetic operation is performed to calculate the PFD value [8].

LOPA has both qualitative and quantitative attributes in its worksheet. The former, qualitative attributes, include the following parameters: target mitigated event likelihood $\left(f_{\mathrm{TMEL}}\right)$ as well as 
consequence $(\mathrm{C})$, since a value of $f_{\text {TMEL }}$ directly depends on the $\mathrm{C}$ value which is determined by experts' consensus. The latter, quantitative attributes, include initiating cause frequency $\left(f_{\text {IC }}\right)$, PFD for independent protection layer $\left(\mathrm{PFD}_{\mathrm{IPL}}\right)$ and intermediate event likelihood $\left(f_{\mathrm{IEL}}\right)$. The relationship among these qualitative and quantitative parameters follows the formula:

$$
P F D_{\text {Required }}=\left\{\begin{array}{l}
\frac{f_{T M E L}}{f_{I E L}} \text { for } f_{T M E L}<f_{I E L} \\
\text { Not required, otherwise }
\end{array}\right.
$$

where $f_{I E L}=f_{I C} \times P F D_{I P L}$

Uncertainty analysis for LOPA has been performed according to the following steps. The first step is to fuzzify the qualitative parameters into membership functions. The qualitative parameters, $\mathrm{C}$ and $f_{\mathrm{TMEL}}$ membership functions are modelled using both trapezoidal and triangular shaped functions. For quantitative parameters, $f_{\mathrm{IC}}$ and $\mathrm{PFD}_{\mathrm{IPL}}$, are assumed to follow uniform distributions due to its large amount of uncertainty. To get the interval of required PFD and SIL, $f_{\mathrm{TMEL}}$ is modelled with the discrete distribution and $f_{\mathrm{IEL}}$ has been obtained by multiplication of $f_{\mathrm{IC}}$ and $\mathrm{PFD}$ IPL

The illustration examples of abovementioned procedures for uncertainty analysis of SIL determination are summarized in Section 4.

\section{CASE STUDIES}

\subsection{System description}

An exemplification study has been performed for the local safety function, the MEG Subsea Injection Pump Dischargepressure safety high alarm. This protection function is to prevent overpressure in thedischarge of MEG injection pump, which is of positive displacement type. Any obstruction at the user point or no MEG injection due to process shutdown might lead to this hazard. To prevent this hazard, MEG injection pump should be stopped on highpressurealarm detected at the pump discharge. There will be not only MEG spill as an environmental consequence, but loss of containment with very high pressure and personnel risk.The dangerous undetected failure includes all possible modes of failure leading to any of the following effects:the transmitter failing to signal high pressure on demand,the logic solver failing to initiate pump stop, the circuit breaker failing to stop the pump motor on demand.For this reason, the MEG pumpis not included in the reliability calculation. Figure 7 shows the configuration of this SIF.

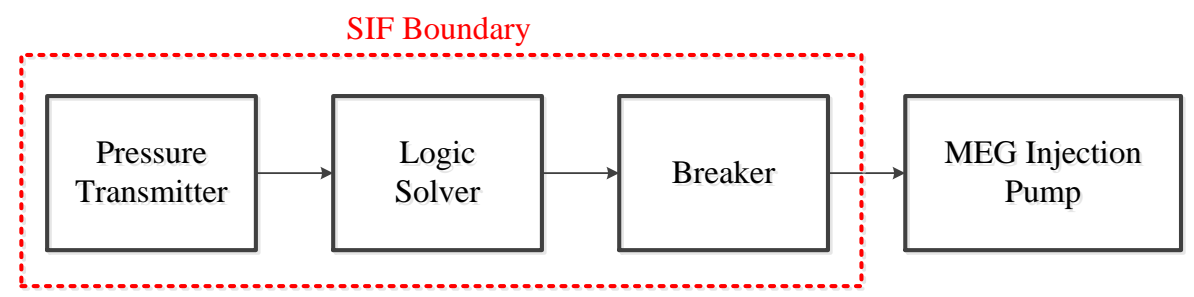

Figure 7.MEG Subsea Injection Pump PSHH Configuration

It is assumed that there are already existing protective measures, so-called non-SIS. One measure isgiven by two pressure safety valves (PSVs) provided on the MEG injection pump discharge, sized for blocked outlet condition. Another measure is the valve that will be open to maintain the pressure in the header. However, if obstruction is sudden, pressure control may not act.

\subsection{Effects of the Uncertainties on Target SIL}




\subsubsection{Sampling method for OLF 070}

As mentioned in Section 2.3, minimum SIL requirements in OLF 070 are derived based on the typical loop assumption and PFD estimationusing industrial verified component reliability data. The uncertainty analysis, applied to the determination of target SIL by the method from OLF 070, can be performed by sampling methods for uncertainty propagation.

To calculate the target SIL of the SIF, the PDS method [19] has been used for maintaining consistency with OLF 070 . Since every component has simple configuration, 1oo1, the average of PFD follows the Equation (3) without consideration of common cause failures [21]. It should be noted that the probability of the so-called test independent failure (TIF) can be added to the PFD to reflect the effect of incomplete testing. OLF 070 takes $\mathrm{P}_{\mathrm{TIF}}$ into consideration when calculating PFD. The values for $\mathrm{P}_{\mathrm{TIF}}$ come from the PDS data handbook [22].

$$
\begin{aligned}
& P F D_{A}=\lambda_{D U} \cdot \frac{\tau}{2}+P_{T I F} \\
& \lambda_{D U}: \text { Rate of dangerous undetected failures } \\
& \tau: \text { Time interval between proof tests } \\
& P_{T I F}: \text { Probability of test independent failures }
\end{aligned}
$$

In addition to the above Equation (3), another model has been used in the case study for the purpose of comparison. In order to replace the effect of imperfect testing with $\mathrm{P}_{\mathrm{TIF}}$, proof test coverage (PTC) is added to the input parameters [10] and the PFD model is modified as follows:

$$
P F D_{B}=P T C \cdot \lambda_{D U} \cdot \frac{\tau}{2}+(1-P T C) \cdot \lambda_{D U} \cdot \frac{T}{2}
$$

$\mathrm{T}$ is the assumed interval of complete testing with which the residual failure modes will be detected. If some failure modes are not able to be tested for, then $\mathrm{T}$ should be taken as the lifetime of the equipment. In this case, $\mathrm{T}$ is assumed to be 5 years, the periodic overhaul duration of the offshore plant where the SIF would be installed.

Among the parameters, $\lambda_{\mathrm{DU}}$ and PTC are assumed to be random variables due to uncertainties from incompleteness of data. Since it is known that the failure rate is usually represented using lognormal distribution [23], the uncertainty of the DU failure rate is given by a lognormal distribution with median equal to the values in Table 4. The error factors are assumed to have the value of 3 [17]. The PTC and $\mathrm{P}_{\mathrm{TIF}}$ are given by uniform distributions with the intervals shown in Table 4 . In regard to proof test coverage, this assumption is due to lack of accumulated data from generic databases in the offshore industry. Also, $\mathrm{P}_{\mathrm{TIF}}$ hasa certain amount of uncertainty because its value is determined by experts' opinion. On the other hand, the number of components and $\tau$ are assumed to be constant, since the uncertainties of configurations and proof test intervals can be controlled [10].

Table 4.Reliability Data for the SIF Components

\begin{tabular}{cccccc}
\hline Component & No. of Components & $\lambda_{\mathrm{DU}}$, perhour & $\mathrm{T}$, hours & PTC, $\%$ & $\mathrm{P}_{\mathrm{TIF}}$ \\
\hline Pressure transmitter & 1 & $0.3 \cdot 10^{-6}$ & 8760 & $80 \sim 99$ & $4.0 \cdot 10^{-4} \sim 6.0 \cdot 10^{-4}$ \\
Logic solver & 1 & $1.0 \cdot 10^{-6}$ & 8760 & $80 \sim 99$ & $3.0 \cdot 10^{-5} \sim 7.0 \cdot 10^{-5}$ \\
Circuit breaker & 1 & $0.2 \cdot 10^{-6}$ & 17520 & $80 \sim 99$ & $3.0 \cdot 10^{-5} \sim 7.0 \cdot 10^{-5}$ \\
\hline
\end{tabular}


The uncertainty propagation has been performed by Monte Carlo simulation. For each simulation run, random values for each uncertain parameter have been generated and then, used as input to calculate target $\mathrm{SIL}_{\mathrm{A}}$ and $\mathrm{SIL}_{\mathrm{B}}$ based on $\mathrm{PFD}_{\mathrm{A}}$ and $\mathrm{PFD}_{\mathrm{B}}$, respectively. A total of 50,000 simulation runs have been performed for the precision of results. The target SIL distributions are shown in Figure8, with the input parameter distributions. Also, the statistics of the target SIL simulation results are reported in Table 5, where $\mathrm{P}_{\alpha}$ represents $\alpha \%$ percentile of each output parameter.
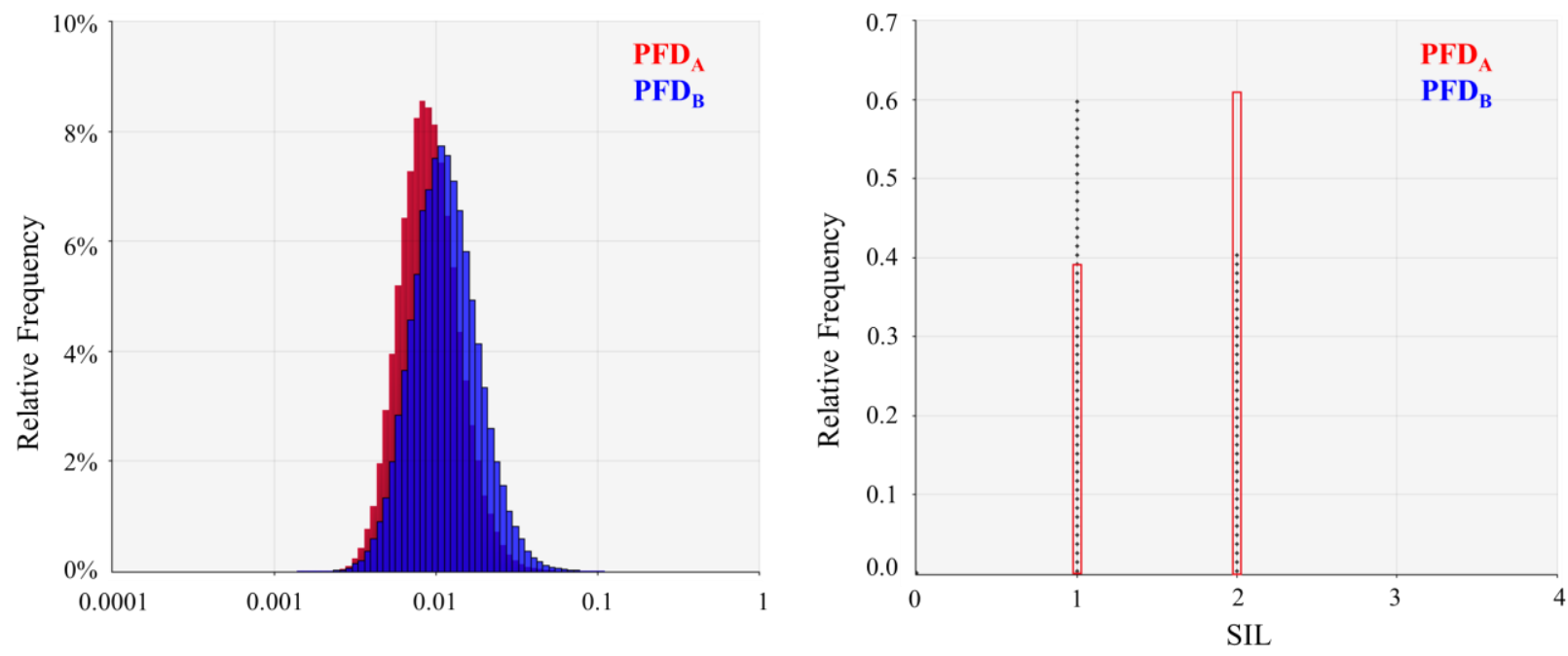

Figure 8.Input Parameters Distributions and Target SIL Distribution obtained by Monte Carlo Simulation

Table 5.Statistics of Target SIL Simulation Results for Different Models

\begin{tabular}{ccccccc}
\hline Output & Mean & $\begin{array}{c}\text { Standard } \\
\text { Deviation }\end{array}$ & $\begin{array}{c}\text { Coefficient of } \\
\text { Variation }\end{array}$ & $\mathrm{P}_{10}$ & $\mathrm{P}_{50}$ & $\mathrm{P}_{90}$ \\
\hline $\mathrm{PFD}_{\mathrm{A}}$ & $9.94 \times 10^{-3}$ & $4.64 \times 10^{-3}$ & $4.67 \times 10^{-1}$ & $5.42 \times 10^{-3}$ & $8.93 \times 10^{-3}$ & $1.56 \times 10^{-2}$ \\
$\mathrm{PFD}_{\mathrm{B}}$ & $1.27 \times 10^{-2}$ & $6.65 \times 10^{-3}$ & $5.24 \times 10^{-1}$ & $6.35 \times 10^{-3}$ & $1.12 \times 10^{-2}$ & $2.07 \times 10^{-2}$ \\
$\mathrm{SIL}_{\mathrm{A}}$ & 1.61 & $4.88 \times 10^{-1}$ & $3.03 \times 10^{-1}$ & 1 & 2 & 2 \\
$\mathrm{SIL}_{\mathrm{B}}$ & 1.40 & $4.91 \times 10^{-1}$ & $3.51 \times 10^{-1}$ & 1 & 1 & 2 \\
\hline
\end{tabular}

\section{$\underline{4.2 .2 F u z z y ~ s e t ~ a p p r o a c h ~ f o r ~ r i s k ~ g r a p h ~}$}

At the end of Section 3.3, the fuzzy set approach has been studied for uncertainty analysis associated to the risk graph model. For this case study, the calibrated risk graph has been used as shown in Figure 9, which conveys the deterministic result of the SIL assessment for the SIF. The first step of the fuzzy set approach is to fuzzify the parameters into membership functions. Parameters used here are listed in Figure 10 with corresponding membership functions, respectively. Membership functions are modelled using both trapezoidal and triangular shaped functions. For parameter P, the mark with a star indicates that $\mathrm{P}_{\mathrm{A}}$ should be selected if only all the following are true; a) facilities are provided to alert the operator that the SIS has failed, b) independent facilities are provided to shutdown such that the hazard can be avoided or which enable all persons to escape to a safe area, c) the time between the 
operator being alerted and a hazardous event occurring exceeds 1 hour or is definitely sufficient for the necessary actions.

After the fuzzification, the fuzzy inference system is modelled using 'If-then rule', for example, If (C is Medium_high) and (F is Low) and (P is High) and (W is Medium_high) then (SIL is SIL 2). In this case study, a total of 52 rules are generatedby experience,summarized in Table 3.The linguistic values are described in Table 6.

The last stage is to defuzzify the results obtained back into a scalar value. There are several methods of defuzzification such as Center-of-Maximum (CoM), Mean-of-Maximum (MoM), Center-of-Area (CoA), etc [24]. For this case, CoA has been used because this method can produce sufficiently accurate results in many cases [25]; the result is shown with its relative frequency respectively in Figure 11.

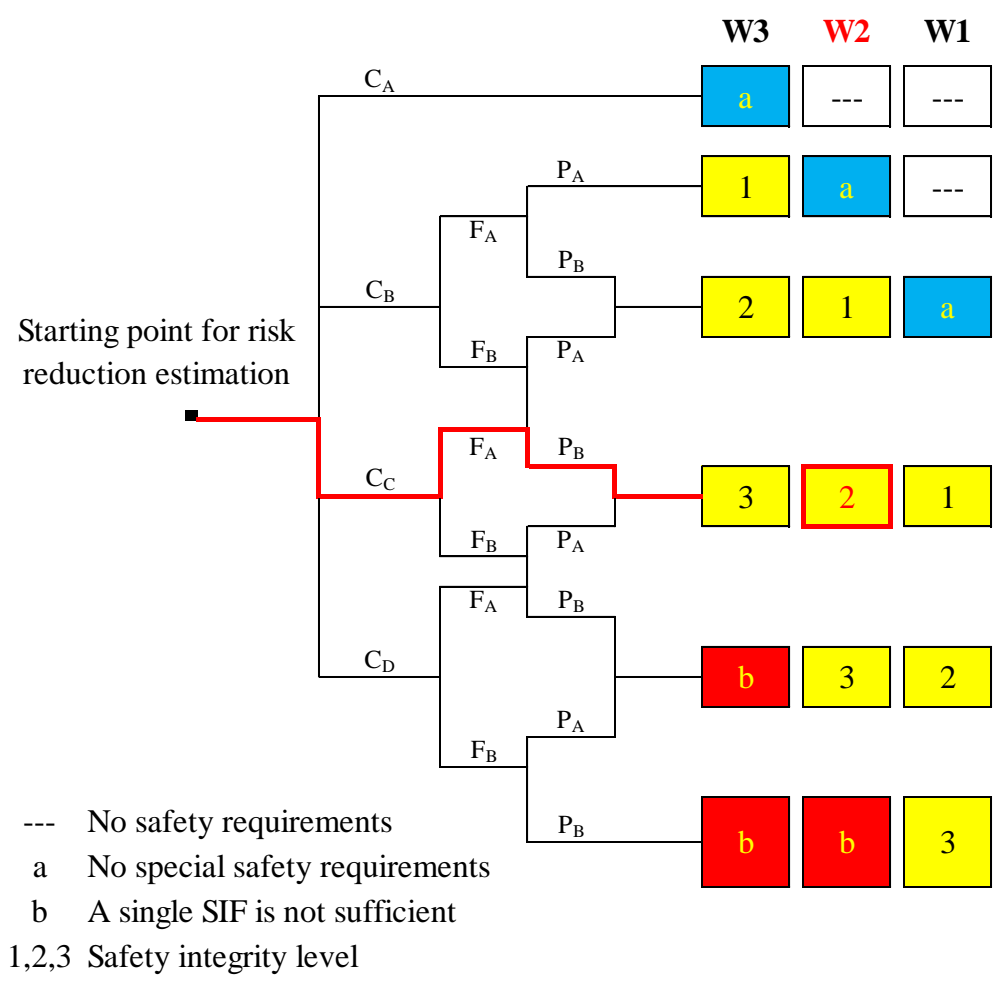

Figure 9.Calibrated Risk Graph and Determined Target SIL for the SIF

Table 6. Linguistic Values of Input Parameters

\begin{tabular}{ccccccc}
\hline $\begin{array}{c}\text { Input } \\
\text { Parameter }\end{array}$ & Very Low & Low & $\begin{array}{c}\text { Medium } \\
\text { Low }\end{array}$ & $\begin{array}{c}\text { Medium } \\
\text { High }\end{array}$ & High & Very High \\
\hline $\mathrm{C}$ & & $\mathrm{C}_{\mathrm{A}}$ & $\mathrm{C}_{\mathrm{B}}$ & $\mathrm{C}_{\mathrm{C}}$ & $\mathrm{C}_{\mathrm{D}}$ & \\
$\mathrm{F}$ & & $\mathrm{F}_{\mathrm{A}}$ & & & $\mathrm{F}_{\mathrm{B}}$ & \\
$\mathrm{P}$ & & $\mathrm{P}_{\mathrm{A}}$ & & & $\mathrm{P}_{\mathrm{B}}$ & \\
$\mathrm{W}$ & & $\mathrm{W}_{0}$ & $\mathrm{~W}_{1}$ & $\mathrm{~W}_{2}$ & $\mathrm{~W}_{3}$ & SIL b \\
SIL & No SIL & SIL a & SIL 1 & SIL 2 & SIL 3 & SIL \\
\hline
\end{tabular}



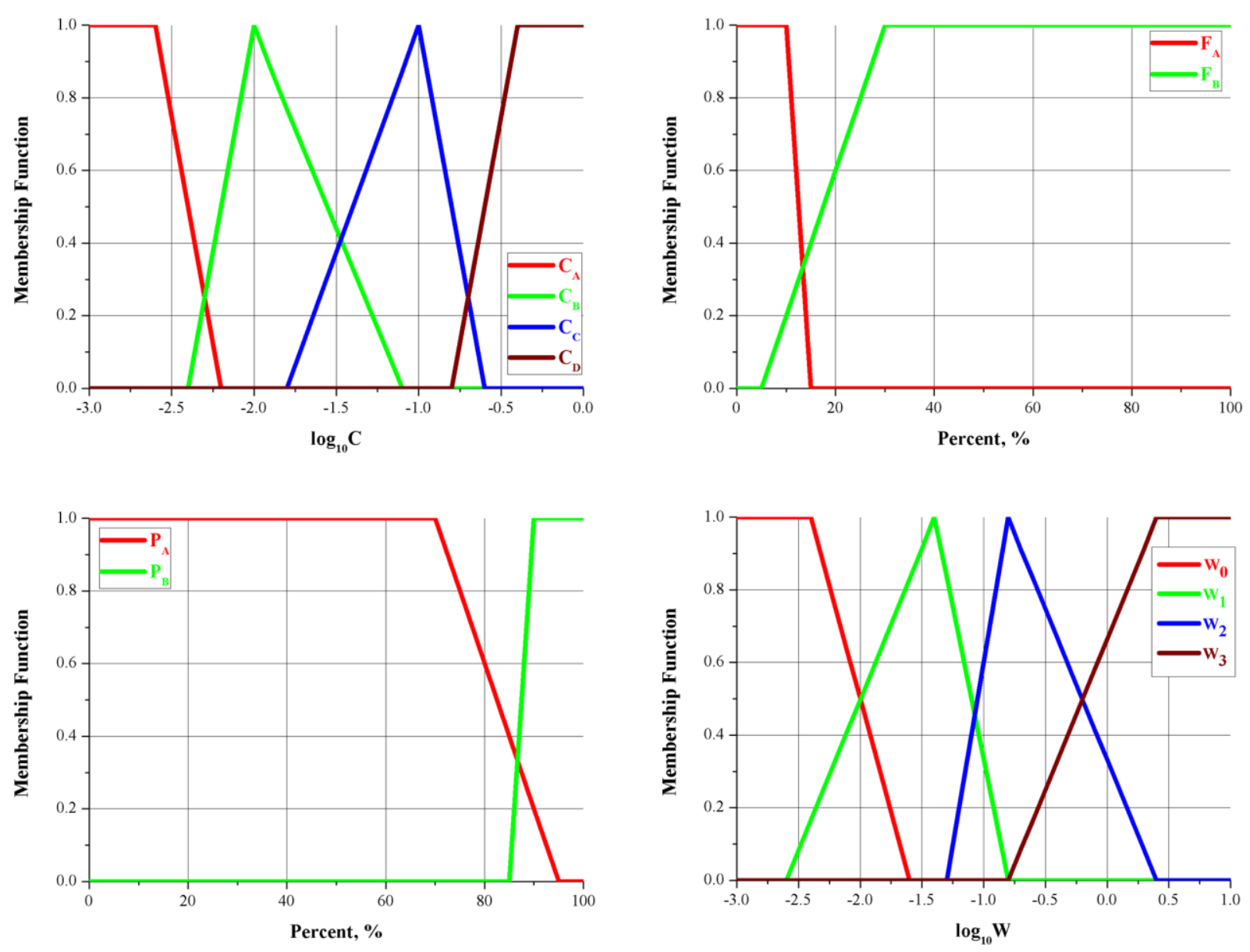

Figure 10.Membership Functions for Risk Graph Parameters

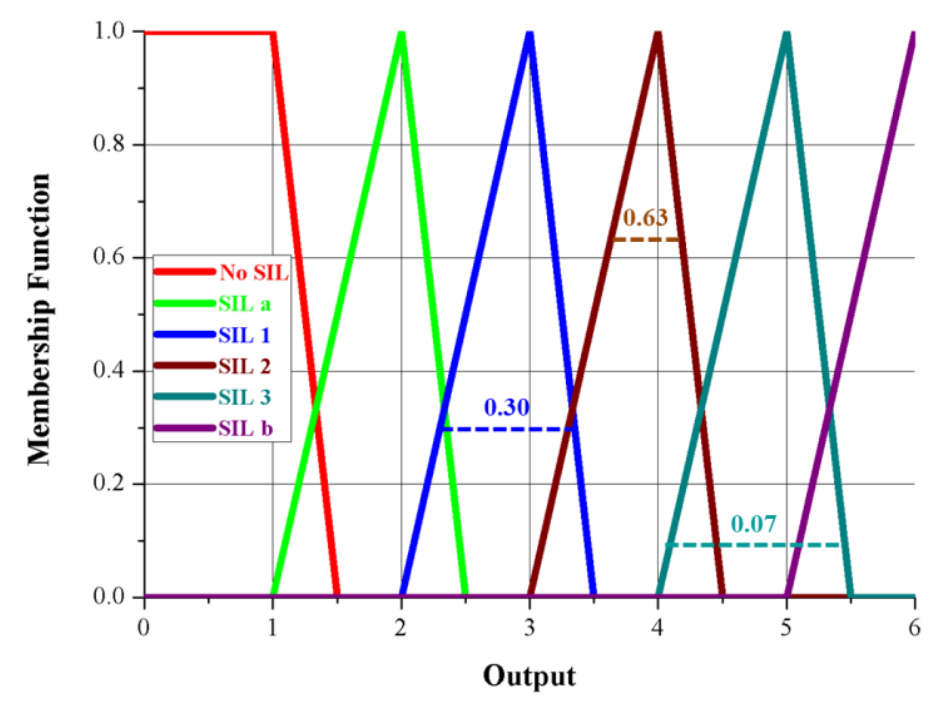

Figure 11.Target SIL Obtained using the Fuzzy Set Approach 


\subsubsection{Combination ofboth sampling method and fuzzy set approach for LOPA}

LOPA has been conducted for the SIF, MEG Subsea Injection Pump DischargePSHH, and the results are shown in Table5. There is a little uncertainty when determining severity level from $C_{C}$ to $C_{D}$. In terms of personal safety, $C_{C}$ applies to serious illness or significant life-shortening effects and $C_{D}$ includes single or multiple employee fatalities. This uncertainty of $\mathrm{C}$-parameter affects the value of $f_{\text {TMEL }}$, from $1.00 \times 10^{-4}$ for $\mathrm{C}_{\mathrm{C}}$ to $1.00 \times 10^{-5}$ for $\mathrm{C}_{\mathrm{D}}$. According to [11], $f_{\mathrm{IC}}$ and $\mathrm{PFD}_{\mathrm{IPL}}$ can be assumed to have the range of values in Table 5. Since the SIF has two PSVs for the purpose of high pressures, $\mathrm{PFD}_{\mathrm{IPL}}$ values are multiplied by 2 . Consequently, $f_{\mathrm{IEL}}$ has minimum of $2.00 \times 10^{-5}$ and maximum of $2.00 \times 10^{-2}$.

Uncertainty analysis for LOPA has been performed according to the following steps. The first step is to fuzzify the qualitative parameters into membership functions. Qualitative parameters, $\mathrm{C}$ and $f_{\text {TMEL }}$, are shown in Figure 12 with corresponding membership functions, respectively. Membership functions are modelled using both trapezoidal and triangular shaped functions. For quantitative parameters, $\mathrm{f}_{\mathrm{IC}}$ and $\mathrm{PFD}_{\mathrm{IPL}}$, are assumed to follow uniform distributions due to its large amount of uncertainty [26]. To get the interval of required PFD and SIL, $f_{\text {TMEL }}$ is modelled with the discrete distribution and $f_{\mathrm{IEL}}$ has been obtained by multiplication of $\mathrm{f}_{\mathrm{IC}}$ and $\mathrm{PFD}_{\mathrm{IPL}}$. Figure 13 and Table8summarizesthe results of uncertainty analysis using both Monte Carlo simulation and fuzzy set approach.

Table 7.LOPA Worksheet

\begin{tabular}{|c|c|c|c|c|c|c|c|c|c|}
\hline \multirow{2}{*}{$\begin{array}{c}\text { SIL } \\
\text { Description }\end{array}$} & \multirow[b]{2}{*}{ Consequence } & \multirow[b]{2}{*}{ TMEL } & \multirow{2}{*}{$\begin{array}{l}\text { Initiating } \\
\text { Cause }\end{array}$} & \multirow[b]{2}{*}{$\mathrm{f}_{\mathrm{IC}}$} & \multicolumn{3}{|c|}{ Independent Protection Layers } & \multirow[b]{2}{*}{ IEL } & \multirow[b]{2}{*}{ SIL } \\
\hline & & & & & BPCS & Alarms & $\begin{array}{c}\text { Add. } \\
\text { Mitigation }\end{array}$ & & \\
\hline $\begin{array}{l}\text { MEG } \\
\text { Subsea } \\
\text { Injection } \\
\text { Pump }\end{array}$ & $\mathrm{C}_{\mathrm{C}}$ or $\mathrm{C}_{\mathrm{D}}$ & $\begin{array}{c}1.0 \mathrm{E}-5 \\
\sim \\
1.0 \mathrm{E}-4\end{array}$ & $\begin{array}{l}\text { High- } \\
\text { high } \\
\text { pressure }\end{array}$ & $\begin{array}{c}1.0 \mathrm{E}-1 \\
\sim \\
1.0 \mathrm{E}-2\end{array}$ & 1 & 1 & $\begin{array}{c}2.0 \mathrm{E}-3 \\
\sim \\
2.0 \mathrm{E}-2\end{array}$ & $\begin{array}{c}2.0 \mathrm{E}-5 \\
\sim \\
2.0 \mathrm{E}-2\end{array}$ & $\begin{array}{l}0 \\
\tilde{3}\end{array}$ \\
\hline
\end{tabular}

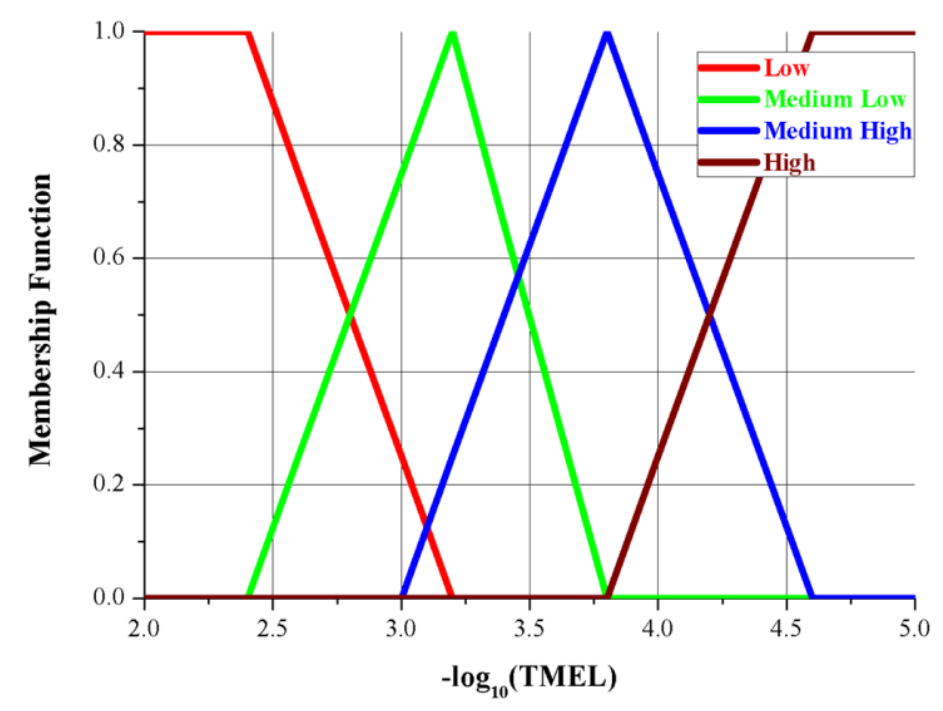

Figure 12.TMEL Obtained using the Fuzzy Set Approach 

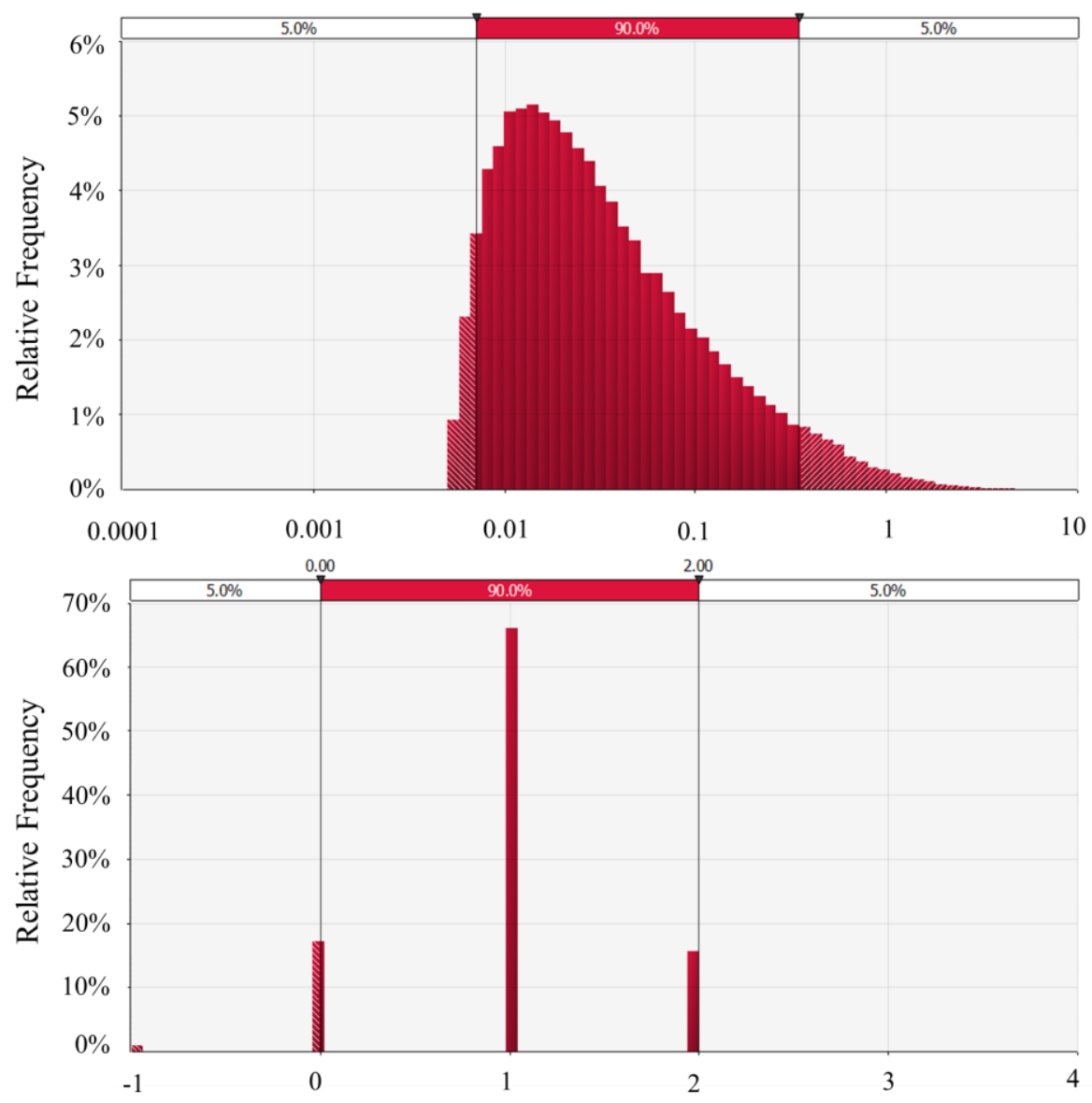

Figure 13.Target SIL Distribution using both Monte Carlo Simulationand Fuzzy Set Approach

Table 8.Statistics of Target SIL using both Monte Carlo Simulation and Fuzzy Set Approach

\begin{tabular}{ccccccc}
\hline Output & Mean & $\begin{array}{c}\text { Standard } \\
\text { Deviation }\end{array}$ & $\begin{array}{c}\text { Coefficient of } \\
\text { Variation }\end{array}$ & $\mathrm{P}_{10}$ & $\mathrm{P}_{50}$ & $\mathrm{P}_{90}$ \\
\hline PFD & $8.35 \times 10^{-2}$ & $1.97 \times 10^{-1}$ & $2.36 \times 10^{1}$ & $8.43 \times 10^{-3}$ & $2.58 \times 10^{-2}$ & $1.87 \times 10^{-1}$ \\
SIL & 0.968 & $6.03 \times 10^{-1}$ & $6.22 \times 10^{-1}$ & 0 & 1 & 2 \\
\hline
\end{tabular}

\subsection{Discussions}

Without considering uncertainty, SIL 2is obtained for the MEG Subsea Injection Pump Discharge pressure safety high alarm when using calibrated risk graph as shown in Figure 9.Moreover, OLF 070 [4]refers that the PSD function for PAHH is required to satisfy SIL 2.From OLF 070, the function is defined to start with the pressure sensor and terminates with closing of the critical valve. On the minimum SIL Table, it is noted that the final element of this function could be different from a valve, e.g. a pump which must be stopped. From the viewpoint of OLF 070, MEG Subsea Injection Pump DischargePSHH is also classified in the PSD function for PAHH and SIL 2 requirement can be applied.

On the contrary, the results show differences when considering also the underlying uncertainties. To model the uncertainties, the following modeling techniques are adapted:

- For risk graph: fuzzy set approach; 
- LOPA: Hybrid fuzzy set approach;

- Minimum SIL: Monte Carlo simulation or Latin Hypercube

For the same SIF, sampling-based $\mathrm{PFD}_{\mathrm{A}}$ and the fuzzy risk graph show similar results in SIL 2. The fuzzy set risk graph of Figure 11 shows target SIL valueshavethe ranges from SIL 1 to SIL 3 while the relative frequenciesare $30 \%, 63 \%$, and $7 \%$ respectively. In this case, the required (target) SIL of the case could be determined as SIL 2 with a conservative consideration. However, a situation is likely to occur when there is no dominant target SIL value. For instance, target SIL results have values from SIL 1 to SIL 3 with relative frequencies of 35\%, 35\%, and 30\%, respectively. In this case, other decision-making guidance should be used for a target SIL determination. It is recommended that independent QRA (Quantitative Risk Assessment)e.g. fire \& explosion analysisshould be performed for supplementary decision-guide. OLF 70 proposes a general approachto verify SIL requirements by application of QRA [4].Sampling-based $\mathrm{PFD}_{\mathrm{B}}$ and the result of LOPA using both methods, Monte Carlo simulation and fuzzy set approach, have derived target SIL values in the range from SIL 0 to SIL 2. Table 9 summarizes the target SIL results on evaluation methods.

Although the distributions of $\mathrm{PFD}_{\mathrm{A}}$ and $\mathrm{PFD}_{\mathrm{B}}$ approximate each other in terms of both location and relative variation, the final outputs are distinguished. It can be guessed that the reason of the difference in target SILs mainly comes from the difference in models between $\mathrm{PFD}_{\mathrm{A}}$ and $\mathrm{PFD}_{\mathrm{B}}$. Since PTC shows more sensitivity than other parameters [10], the outputs of the analysis by the $\mathrm{PFD}_{\mathrm{B}}$ model including PTC can be more affected by the parameter uncertainty.

Table 9. Summary of Target SIL on Method

\begin{tabular}{lccc}
\hline \multirow{2}{*}{ Method } & \multicolumn{3}{c}{ Target SIL } \\
\cline { 2 - 4 } & $\mathrm{P}_{10}$ & $\mathrm{P}_{50}$ & $\mathrm{P}_{90}$ \\
\hline Sampling method for OLF-070 with Equation (3) & 1 & 2 & 2 \\
Sampling method for OLF-070 with Equation (3) & 1 & 1 & 2 \\
Fuzzy set approach for Risk graph $\dagger$ & 1 & 2 & 3 \\
Fuzzy set + Sampling for LOPA & 0 & 1 & 2 \\
\hline
\end{tabular}

$\dagger$ The relative frequency is $0.30,0.63$, and 0.07 for $\mathrm{P}_{10}, \mathrm{P}_{50}$, and $\mathrm{P}_{90}$, respectively.

\section{CONCLUSION}

This paper has looked into the problem of treating uncertainty in the target SIL determination phase and proposed a practical approach for offshore industry. In particular, the risk graph method, LOPA, and minimum SIL requirement in OLF 070 have been introduced and studied with respect to the analysis of the uncertainty that affects their SIL outcomes.

Both parameter and model uncertainty contribute to uncertainties in the determined target SIL values, when using different methodologies such asthe risk graph, LOPA, or minimum SIL requirement from OLF 070. To investigate the effect of uncertainties, the fuzzy set approach and Monte Carlo simulation have been used for risk graph and OLF 070 minimum SIL requirement, respectively. For LOPA, the hybrid approach, using fuzzy set approach and Monte Carlo method together, has been proposed to reflect both qualitative and quantitative features of the uncertainty. 
According to the case study results summarized in Section 4, the fuzzy set approach based on the risk graph method, LOPA with Monte Carlo simulation and fuzzy set approach and OLF 70 minimum SIL Table by using Monte Carlo simulation show reliable results for SIL determination. LOPA with Monte Carlo simulation and fuzzy set approach shows advantages of less uncertainty than the fuzzy set approachfor SIL determination, if a sufficientinformation available.

The percentage of $80 \sim 90$ of all identified SIFs in offshore facilities are usually assigned as SIL 1 or SIL 2. Therefore, a guideline on how to apply the methods considered in the paper for SIL determination can be suggested in offshore industry as follows. First, the fuzzy set approach can be used for overall SIL determination, while LOPA with Monte Carlo simulation and fuzzy set approach can be considered as a supplementary tool in order to verify the requirement of SIFs expected to be SIL 3 and strongly disputing between participants for the assigned SIL.

For a future work, practical procedures will be proposed to combine QRA with uncertainty analysis of SIL determination in order to verify or reduce the uncertainty in the results.

\section{Acknowledgements}

The authors would like to thank the Outfitting System Research Department of Corporate Technology Institute, Hyundai Heavy Industries for supplying technical information and comments.

\section{References}

[1] M.A. Lundteigen. "Safety instrumented systems in the oil and gas industry: concepts and methods for safety and reliability assessments in design and operation", Doctoral thesis, Norwegian University of Science and Technology (NTNU),2009, Trondheim, Norway.

[2] IEC 61508. "Functional safety of electrical/electronic/programmable electronic safety-related systems," International Electrotechnical Commission, 2010, Geneva.

[3] IEC 61511."Functional safety-safety instrumented systems for the process industry," International Electrotechnical Commission, 2010, Geneva.

[4] OLF-070. "Application of IEC 61508 and IEC 61511 in the Norwegian petroleum industry," Technical report. The Norwegian Oil Industry Association, 2004, Stavanger, Norway.

[5] R. Nati-Said, F. Zidani, and N. Ouzraoui. "Fuzzy risk graph model for determining safety integrity level," International Journal of Quality, Statistics, and Reliability, volume 2008, article ID 263895, (2008).

[6] R. Ouache and A. Adham. "Safety instrumented systems between reliability and fuzzy," International Journal of Information Systems and Engineering, volume 2(1), pp. $173 \sim 185$, (2014).

[7] O.Y. Abul-Haggag and W. Barakat. "Application of fuzzy logic for the determination of safety integrity in light of IEC 61508 \& 61511 standards," International Journal of Emerging Technology and Advanced Engineering, volume 3, pp.41-48, (2013).

[8] F. Innal, Y. Dutuit, and M. Chebila. "Monte Carlo analysis and fuzzy sets for uncertainty propagation in SIS performance assessment," International Journal of Mathematical, Computational, Physical and Quantum Engineering, volume 7(11), pp. 1063 1071, (2013).

[9] N.S. Arunraj, S. Mandal and J. Maiti. "Modeling uncertainty in risk assessment: An integrated approach with fuzzy set theory and Monte Carlo simulation," Accident Analysis and Preventiion, volume 55, pp. $242 \sim 255$, (2013).

[10] S. Kim, K. Chang,and Y. Kim. "Risk-based design for implementation of SIS functional safety in the offshore industry",Proceedings of the European safety and reliability conference 2013 (ESREL 2013), pp. 1875-80, (2013), London.

[11] CCPS. "Layer of protection analysis: simplified process risk assessment," CCPS, 2001, NY, USA.

[12] E. Zio. "The Monte Carlo simulation method for system reliability and risk analysis," Springer, 2013, London, UK. 
[13] E. Zio and T. Aven. "Industrial disasters: extreme events, extremely rare. Some reflections on the treatment of uncertainties in the assessment of the associated risks," Process Safety and Environmental Protection, volume 91, pp.31-45, (2013).

[14] T. Aven and E. Zio. "Model output uncertainty in risk assessment," International Journal of Performability Engineering, volume 9(5), pp.475-486, (2013).

[15] T. Aven and E. Zio. "Some considerations on the treatment of uncertainties in risk assessment for practical decision making," The Journal of Reliability Engineering and System Safety, volume 96, pp.64-74, (2011).

[16] M. Abrahamsson. "Uncertainty in quantitative risk analysis -characterization and methods of treatment," Doctoral thesis, Lund University, 2002, Lund, Sweden.

[17] H. Jin, M.A. Lundteigen, and M. Rausand. "Uncertainty assessment of reliability estimates for safety instrumented systems", Proceedings of the European safety and reliability conference 2012 (ESREL 2012), pp. 2213-21, (2012), London.

[18] A.F. Janbu. "Treatment of uncertainties in reliability assessment of safety instrumented systems", Master's thesis, Norwegian University of Science and Technology (NTNU), 2009, Trondheim, Norway.

[19] Sintef. "Reliability prediction methods for safety instrumented systems, PDS methodhandbook," Sintef, 2013, Trondheim, Norway.

[20] P. Baraldi, R. Flage, T. Aven, and E. Zio. "Uncertainty in risk assessment," Wiley, 2014, Chichester, UK.

[21] M. Rausand. "Reliability of safety-critical systems," John Wiley \& Sons, Inc., 2014, Hoboken, New Jersey.

[22] Sintef. "Reliability data for safety instrumented systems, PDS data handbook," Sintef, 2013, Trondheim, Norway.

[23] NASA, "Probabilistic risk assessment procedures guide for NASA managers and practitioners," Technical report, NASA Office of Safety and Mission Assurance, 2002, Washington, DC.

[24] C. Simon, M. Sallak, and J.F. Aubry. "SIL allocation of SIS by aggregation of experts' opinions", Proceedings of the European safety and reliability conference 2007 (ESREL 2007), 2007, Stavanger, Norway.

[25] I. Elaamvazuthi, P. Vasant, and J. Webb, "The application of Mamdani fuzzy model for auto zoom function of a digital camera," International Journal of Computer Science and Information Security, volume 6, pp.244-249, (2009).

[26] R. Flage, P. Baraldi, E. Zio, and T. Aven. "Probability and possibility-based representations of uncertainty in fault tree analysis," Risk Analysis, volume 33(1), pp.121-133, (2013). 